\title{
Analisis Video Comments to Video Views Ratio Youtube Pada 5 Perusahaan Produsen Mobil Terkemuka Di Indonesia
}

\author{
Kadek Widi Artha \\ kadek.widiartha100@gmail.com
}

\begin{abstract}
Youtube is a video sharing website created by three former PayPal employees in February two thousand and five. This site allows users to upload, watch and share videos. Apart from that, there is also amateur content such as video blogs, short original videos, and educational videos. This study uses a quantitative exploratory method, and will calculate using the ratios that exist on Youtube. In this study, it is explained that there are 10 ratios that exist on Youtube social media and are relevant to be used as a medium for measuring the credibility of existing accounts. This study only focuses on calculating the credibility of the Video Comments to Video Views Ratio in the 5 Leading Car Manufacturers in Indonesia. The 5 leading car manufacturers in Indonesia, including: Toyota Indonesia, WeloveHonda Indonesia, Daihatsu Sahabatku, Suzuki Global, Nissan Indonesia. The purpose of this study is to determine the credibility of the performance of the Youtube accounts of 5 Leading Car Manufacturers in Indonesia using Video Comments to Video Views Ratio.
\end{abstract}

\begin{abstract}
ABSTRAK
Youtube adalah sebuah situs web berbagi video yang dibuat oleh tiga mantan karyawan PayPal pada Februari 2005. Situs ini memungkinkan pengguna mengunggah, menonton, dan berbagi video. Selain itu ada pula konten amatir seperti blog video, video orisinal pendek, dan video pendidikan. Penelitian ini menggunakan metode eksploratif kuantitatif, dan akan menghitung menggunakan rasio-rasio yang ada pada Youtube. Pada penelitian ini menjelaskan bahwa terdapat 10 rasio yang ada pada sosial media Youtube dan relevan untuk digunakan sebagai media ukur dari kredibilitas akun yang ada. Penelitian ini hanya berfokus untuk menghitung kredibilitas Video Comments to Video Views Ratio pada 5 Perusahaan Produsen Mobil Terkemuka di Indonesia. Adapun 5 Perusahaan Produsen Mobil Terkemuka di Indonesia, diantaranya yaitu: Toyota Indonesia, WeloveHonda Indonesia, Daihatsu Sahabatku, Suzuki Global, Nissan Indonesia. Tujuan dari penelitian ini adalah untuk mengetahui kredibilitas performa dari akun Youtube 5 Perusahaan Produsen Mobil Terkemuka di Indonesia menggunakan ratio Video Comments to Video Views Ratio.
\end{abstract}

Keyword: Media sosial; Youtube; Rasio Youtube; Kredibilitas Akun Sosial Media. 


\section{PENDAHULUAN}

Kemajuan Teknologi informasi dan Komunikasi telah membuka tahap baru bagi masyarakat untuk memperoleh informasi secara otonom. Sekat-sekat informasi dengan sendirinya menghilang oleh inisiatif kuat individu yang ingin mengetahui lebih jauh apa yang terjadi sekitarnya. Adanya Media sosial mampu memberikan pengaruh yang sangat besar, hingga saat ini media sosial dijadikan sarana berkomunikasi dalam melakukan aktifitas keseharian bersosial di masyarakat. Melakukan komunikasi tidak hanya dapat dilakukan secara fisik, tetapi juga dapat dilakukan dengan menggunakan berbagai aplikasi media sosial di dunia maya. Keunggulan layanan aplikasi sosial media yaitu mampu memberikan ruang komunikasi dua arah antara konsumen dengan perusahaan dan konsumen dengan konsumen (Rosana, 2010).

Salah satu aplikasi sosial media yang sering digunakan dan memiliki pengaruh besar adalah YouTube. Penelitian ini dilakukan dengan tujuan untuk menemukan rasio-rasio yang terdapat pada akun YouTube. Rasio-rasio ini yang nantinya akan digunakan untuk mengukur performa sebuah akun secara matematis. Penelitian ini dilakukan dengan menggunakan metode ekploratif untuk menemukan variabel-variabel yang terdapat pada akun YouTube. Variabel tersebut yang nantinya akan dibandingkan dan disandingkan untuk diuji relevansinya sehingga menjadi rasio yang relevan. Rasio yang relevan akan digunakan untuk menilai performa setiap akun yang ada pada sosial media YouTube. Hasil dari penelitian sosial media youtube ini menunjukan bahwa terdapat 6 variabel, variabel tersebut diantaranya yaitu post, subscriber, likes, dislikes, views, comments. Keenam variabel tersebut yang nantinya akan dibandingkan dan disandingkan sehingga menemukan 10 rasio yang relevan. Manfaat yang dapat diambil dari penelitian ini yaitu kedepannya dapat menilai, mengukur serta membandingkan kredebilitas dari setiap akun youtube dengan mudah menggunakan 10 rasio yang telah ditemukan (Hendika Permana, 2021).

Cukup banyak akun perusahaan-perusahaan terkenal yang ada pada Youtube, contohnya seperti perusahaan produsan mobil di Indonesia. Adapun 5 Perusahaan Produsen Mobil Terkemuka Di Indonesia, diantaranya yaitu: Toyota Indonesia, WeloveHonda Indonesia, Daihatsu Sahabatku, Suzuki Global, Nissan Indonesia (Tagarberita, 2020).

Penelitian ini menggunakan metode eksploratif kuantitatif, dan akan menghitung menggunakan rasio-rasio yang ada pada Youtube (Mudjiyanto, 2018). Pada penelitian ini menjelaskan bahwa terdapat 10 rasio yang ada pada sosial media Youtube dan relevan untuk digunakan sebagai media ukur kredibilitas akun yang ada. Penelitian ini hanya berfokus untuk menghitung kredibilitas Video

\section{Comments to Video Views Ratio pada 5 Perusahaan Produsen Mobil Terkemuka Di}

Indonesia. Tujuan dari penelitian ini adalah mengetahui kredibilitas performa dari akun Youtube 5 Perusahaan Produsen Mobil Terkemuka Di Indonesia menggunakan Video Comments to Video Views Ratio (Tagarberita, 2020). 


\section{TINJAUAN PUSTAKA}

Perkembangan teknologi informasi membawa sebuah perubahan dalam masyarakat. Lahirnya media sosial menjadikan pola perilaku masyarakat mengalami pergeseran baik budaya, etikan dan norma yang ada. Indonesia dengan jumlah penduduk yang besar dengan berbagai kultur suku, ras dan agama yang beraneka ragam memiliki banyak sekali potensi perubahan sosial. Dari berbagai kalangan dan usia hampir semua masyarakat Indonesia memiliki dan menggunakan media sosial sebagai salah satu sarana guna memperoleh dan menyampaikan informasi ke publik (Hager \& Wellein, 2021).

Youtube adalah sebuah situs web berbagi video yang dibuat oleh tiga mantan karyawan PayPal pada Februari 2005. Situs ini memungkinkan pengguna mengunggah, menonton, dan berbagi video. Perusahaan ini berkantor pusat di San Bruno, California, dan memakai teknologi Adobe Flash Video dan HTML5 untuk menampilkan berbagai macam konten video buatan pengguna, termasuk klip film, klip TV, dan video musik. Selain itu ada pula konten amatir seperti blog video, video orisinal pendek, dan video pendidikan (Youtube, 2005).

Dengan banyaknya pengguna youtube di Indonesia menimbulkan kegemaran baru, kegemaran tersebut dapat menciptakan penghasilan baru bagi para pengguna youtube tersebut. Youtube merupakan suatu wadah untuk menciptakan suatu popularitas baru dengan bertujuan untuk mendapatkan suatu keuntungan. Tidak sedikit para artis televisi berpindah haluan menjadi artis youtube dikarenakan youtube lebih diminati oleh masyarakat daripada televisi, hal ini sesuai dengan slogan dari youtube itu sendiri yaitu "youtube lebih dari sekedar TV". Keuntungan yang didapatkan di dalam youtube dapat berupa suatu popularitas atau bahkan penghasilan tambahan . dengan pengaksesan dan peraihan penghasilan yang mudah membuat youtube menjadi salah satu lahan pekerjaan (Youtube, 2005).

\section{METODE PENELITIAN}

Pada penelitian ini metode yang digunakan yaitu metode eksploratif kuantitatif yang dimana berfungsi untuk mengetahui kredibilitas dari performa akun Youtube 5 Perusahaan Produsen Mobil Terkemuka Di Indonesia. Metode eksploratif merupakan penelitian yang memiliki tujuan untuk melakukan eksplorasi atau memperdalam pengetahuan mengenai suatu hal yang baru, guna merumuskan permasalahan secara terperinci (Mudjiyanto, 2018).

Tujuan dari penelitian ini yaitu mengetahui nilai kredibillitas dari performa akun Youtube 5 Perusahaan Produsen Mobil Terkemuka Di Indonesia. Ada beberapa langkah yang harus dilakukan dalam penelitian ini, sehingga mampu menemukan peringkat pertama akun Youtube dari perusahaan produsen mobil di indoneisa yang memiliki performa terbaik. Langkah-langkah yang dilakukan pada penelitian ini, diantaranya yaitu :

1. Melakukan Pencarian Pada Website Untuk Menentukan Objek yang Akan Dianalisa. Pencarian ini dilakukan pada beberapa halaman website yang menyediakan informasi mengenai objek yang akan di teliti. Setelah ekslorasi selesai dilakukan, sehingga ditemukan nama-nama Perusahaan produsen mobil terkemuka di Indonesia yang akan dijadikan objek 
analisa. Setelah melakukan pencarian pada halaman website, maka langkah selanjutnya yaitu mencari nama akun Youtube dari masing-masing perusahaan produsen mobil. Dan Pastikan semua perusahaan mobil memiliki akun pada aplikasi sosial media Youtube.

2. Menghitung Nilai Rata-Rata Variable Dari 5 Perusahaan Produsen Mobil Terkemuka Di Indonesia. Pada langkah ini, peneliti menghitung nilai variable video comments dan variable video views. Variabel merupakan salah satu komponen penting yang dibutuhkan peneliti dalam sebuah penelitian. Variabel mencakup segala sesuatu yang ditetapkan untuk mendapatkan informasi mengenai hal tersebut hingga bisa ditarik kesimpulannya (Kumparan, 2020). Untuk menghitung nilai rata-rata dari variabel video comments dan variabel video views yaitu dengan cara mengambil minimal 10 postingan dari setiap akun Youtube kemudian di hitung sehingga menemukan nilai rata-rata dari masing-masing variabel.

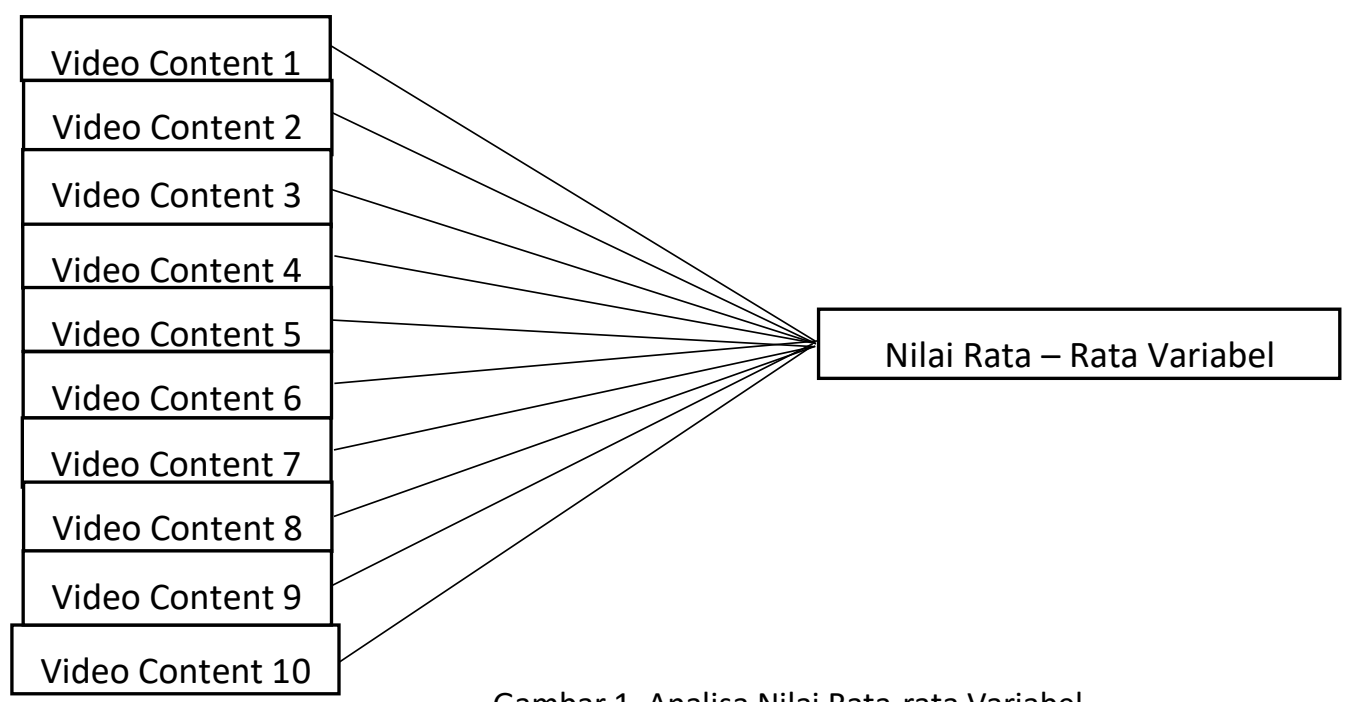

Gambar 1. Analisa Nilai Rata-rata Variabel

3. Menghitung Nilai Kredibilitas Rasio

Untuk menghitung nilai kredibilitas dari video comments to video views ratio, peneliti menggunakan cara membagi nilai variabel pertama dengan nilai variabel kedua. Jika video comments memiliki nilai 100 dan video views memiliki nilai 300, maka cara menghitungnya yaitu $100: 300=0,3$. Dengan begitu nilai dari video comments to video views ratio adalah 0,3 . 


\section{Menentukan Peringkat Pada Akun Youtube}

Pada langkah terakhir yang dilakukan pada penelitian ini yaitu menentukan peringkat pada masing-masing rasio yang ada. Pada penentuan peringkat perlu melihat karakteristik dari rasio yang di teliti. Jika mendapatkan karakteristik rendah, maka objek yang memiliki nilai terendah akan mendapatkan angka 5 dan objek yang memiliki nilai tertinggi akan mendapatkan angka 1. Namun jika rasio memiliki karakteritik tinggi maka objek yang mendapatkan nilai tinggi akan mendapatkan angka 5 dan objek yang mendapatkan nilai terendah akan mendapatkan angka 1 . Setelah mendapatkan hasil kredibilitas ratio maka dapat disimpulkan objek yang mana mendapatkan peringkat 1 sampai dengan peringkat 5 .

Dari hasil penelitian ini mendapatkan karakteristik tinggi jadi objek yang mendapatkan nilai tinggi akan mendapatkan angka 5 dan objek yang mendapatkan nilai terendah akan mendapatkan angka 1. 


\section{HASIL DAN PEMBAHASAN}

Akun Youtube Dari 5 Perusahaan Produsen Mobil Terkemuka Di Indonesia, diantaranya : 1.

\section{Toyota Indonesia}

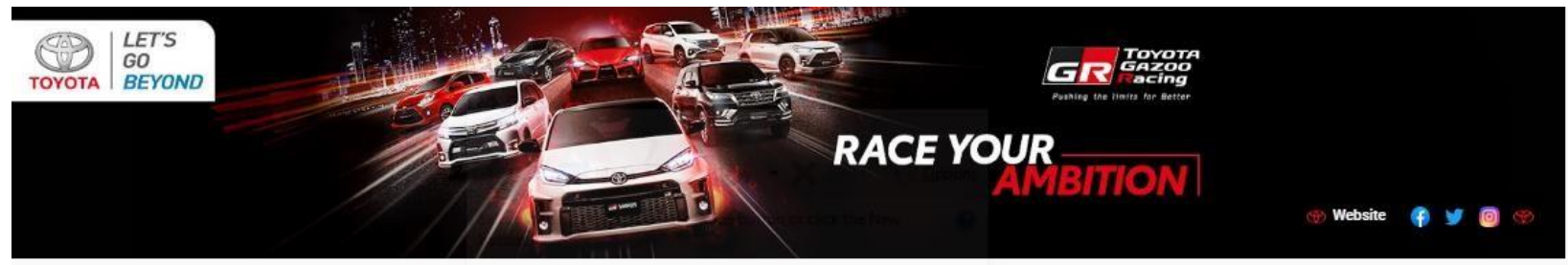

(†) Toyotalndonesia

$639 \mathrm{rb}$ subscriber

\section{WeloveHonda Indonesia}

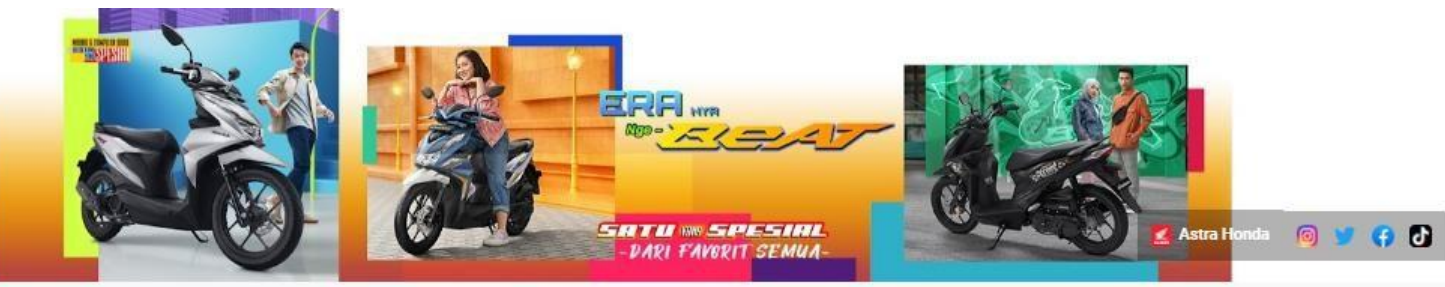

Welovehonda Indonesia $399 \mathrm{rb}$ subscriber

\section{Daihatsu Sahabatku}

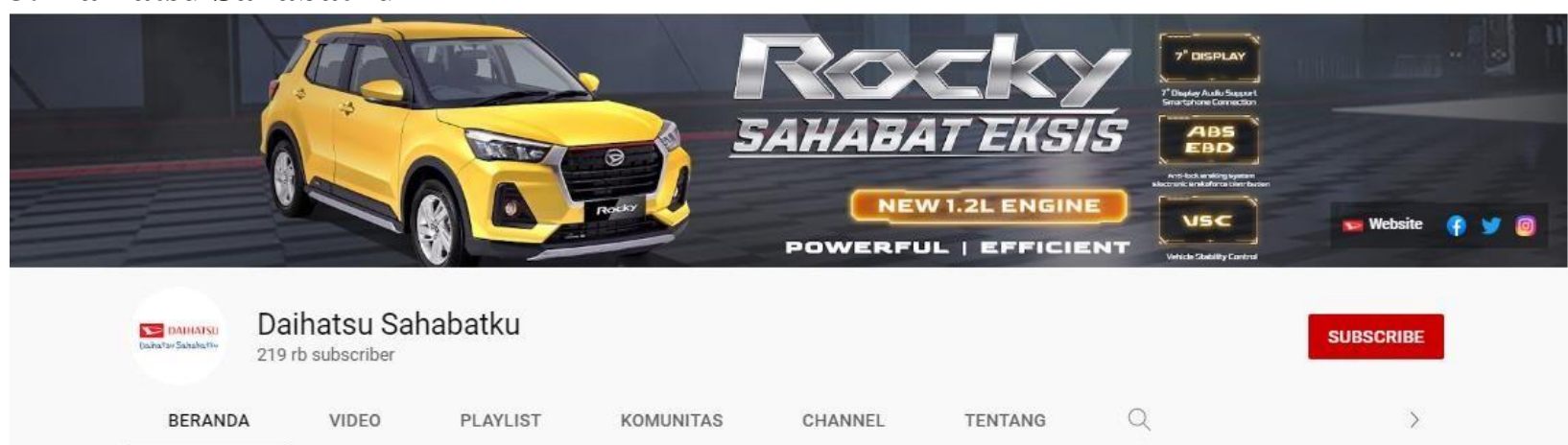

Gambar 3. Akun Youtube Daihatsu Sahabatku

Sumber : https://www.youtube.com/user/DaihatsuSahabatku (akses pada 21-10-2021) 


\section{Suzuki Global}
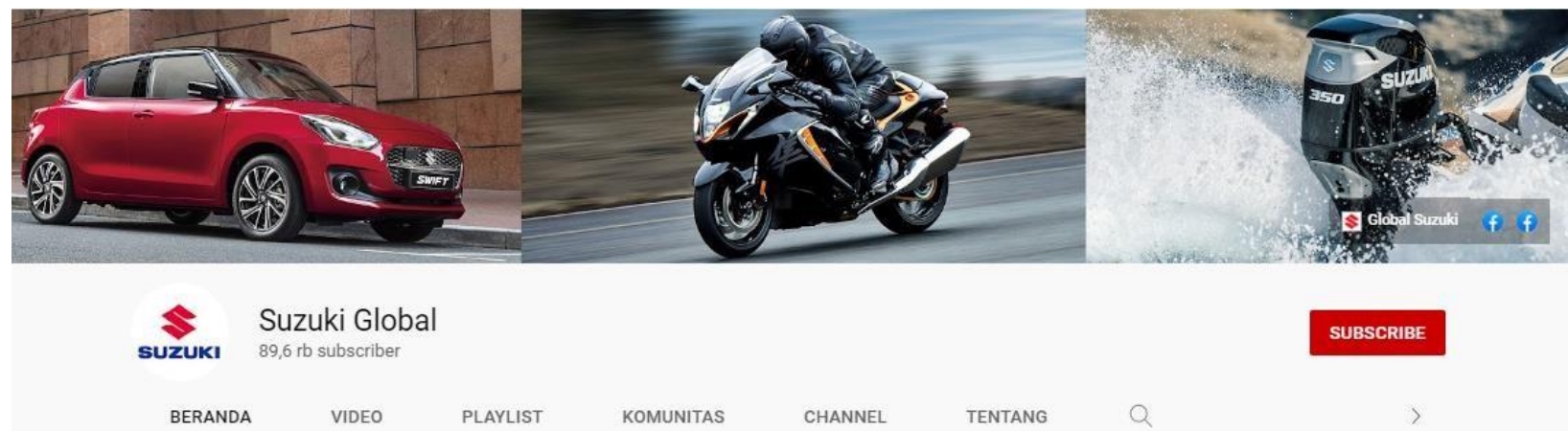

Gambar 4. Akun Youtube Suzuki Global

Sumber : https://www.youtube.com/c/SUZUKIWayofLife (akses pada 21-10-2021)

\section{Nissan Indonesia}

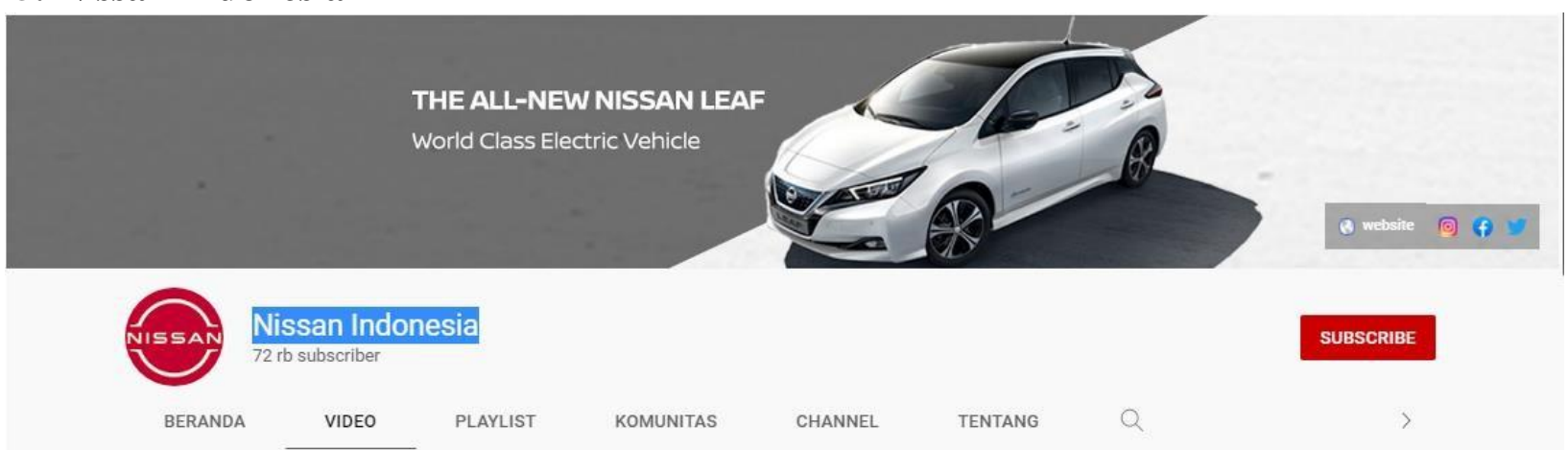

Gambar 5. Akun Youtube Nissan Indonesia

Sumber : https://www.youtube.com/c/NissanIndonesiaChannel (akses pada 21-10-2021)

Dari kelima akun Youtube dari 5 Perusahaan Produsen Mobil Terkemuka Di Indonesia, peneliti menemukan nilai dari masing-masing variabel yang ada untuk menghitung rasio Video Comments to Video Views dari setiap akun. Pada akun Youtube terdapat 6 variabel, diantaranya yaitu :
1. Variable Post
4. Variable Dislikes
2. Variable Subscriber
5. Variable Views
3. Variable Likes
6. Variable Comments

Dari keenam variabel tersebut peneliti hanya fokus untuk menemukan hasil dari 2 variabel, yaitu:

\section{Video Comments \\ 2. Video Views}

Dari kedua variabel tersebut kemudian dianalisa sehingga menemukan nilai rata-rata dari variabel video comments dan variabel video views. Untuk menghitung nilai rata-rata dari variabel video comments dan variabel video views yaitu dengan cara mengambil minimal 10 postingan kemudian di hitung sehingga menemukan nilai rata-rata dari masing-masing 
variabel. Berikut merupakan tabel nilai rata-rata dari masing-masing Perusahaan Produsen Mobil Terkemuka Di Indonesia, yaitu:

Tabel 1. Analisa Nilai Rata-Rata Nilai Variabel Video Comments dan Video Views Akun Toyota Indonesia

\begin{tabular}{|c|c|c|}
\hline No & Video Comments & Video Views \\
\hline $\mathbf{1}$ & 24 & 3.330 \\
\hline $\mathbf{2}$ & 4 & 1.242 \\
\hline $\mathbf{3}$ & 3 & 669 \\
\hline $\mathbf{4}$ & 16 & 19.803 \\
\hline $\mathbf{5}$ & 9 & 1.449 \\
\hline $\mathbf{6}$ & 4 & 1.200 \\
\hline $\mathbf{7}$ & 9 & 1.100 .000 \\
\hline $\mathbf{8}$ & 3 & 987 \\
\hline $\mathbf{9}$ & 3 & 1.200 .000 \\
\hline $\mathbf{1 0}$ & 5 & 234.000 \\
\hline Total & $\mathbf{8}$ & $\mathbf{2 5 6 . 2 6 8}$ \\
\hline
\end{tabular}

Sumber: Pengolah Data Excel

Tabel 2. Analisa Nilai Rata-Rata Nilai Variabel Video Comments dan Video Views Akun WeloveHonda Indonesia

\begin{tabular}{|c|c|c|}
\hline No & Video Comments & Video Views \\
\hline $\mathbf{1}$ & 5 & 2.038 \\
\hline $\mathbf{2}$ & 22 & 1.747 \\
\hline $\mathbf{3}$ & 40 & 4.064 .550 \\
\hline $\mathbf{4}$ & 4 & 2.878 \\
\hline $\mathbf{5}$ & 9 & 2.037 \\
\hline $\mathbf{6}$ & 15 & 1.719 \\
\hline $\mathbf{7}$ & 58 & 2.300 .000 \\
\hline $\mathbf{8}$ & 21 & 1.960 \\
\hline $\mathbf{9}$ & 82 & 4.500 .000 \\
\hline $\mathbf{1 0}$ & 33 & 5.904 \\
\hline Total & $\mathbf{2 9}$ & $\mathbf{1 . 0 8 8 . 2 8 3}$ \\
\hline
\end{tabular}

Sumber: Pengolah Data Excel

Tabel 3. Analisa Nilai Rata-Rata Nilai Variabel Video Comments dan Video Views Akun Daihatsu Sahabatku 


\begin{tabular}{|c|c|c|}
\hline No & Video Comments & Video Views \\
\hline $\mathbf{1}$ & 1 & 57 \\
\hline $\mathbf{2}$ & 5 & 1.975 \\
\hline $\mathbf{3}$ & 46 & 56.239 \\
\hline $\mathbf{4}$ & $1 / 2$ & 36.956 \\
\hline $\mathbf{5}$ & $1 / 2$ & 48.679 \\
\hline $\mathbf{6}$ & 53 & 98.917 \\
\hline $\mathbf{7}$ & 15 & 3.845 \\
\hline $\mathbf{8}$ & 1 & 2.362 \\
\hline $\mathbf{9}$ & 3 & 1.889 \\
\hline $\mathbf{1 0}$ & 9 & 2.278 \\
\hline Total & $\mathbf{1 5}$ & $\mathbf{2 5 . 3 2 0}$ \\
\hline
\end{tabular}

Sumber: Pengolah Data Excel

Tabel 4. Analisa Nilai Rata-Rata Nilai Variabel Video Comments dan Video Views Akun Suzuki Global

\begin{tabular}{|c|c|r|}
\hline No & Video Comments & \multicolumn{1}{|c|}{ Video Views } \\
\hline $\mathbf{1}$ & 240 & 126.000 \\
\hline $\mathbf{2}$ & 211 & 123.000 \\
\hline $\mathbf{3}$ & 2 & 7.623 \\
\hline $\mathbf{4}$ & 5 & 5.921 \\
\hline $\mathbf{5}$ & 1 & 2.587 \\
\hline $\mathbf{6}$ & 4 & 4.183 \\
\hline $\mathbf{7}$ & 2 & 1.835 \\
\hline $\mathbf{8}$ & 3 & 1.065 \\
\hline $\mathbf{9}$ & 1 & 967 \\
\hline $\mathbf{1 0}$ & 27 & 9.113 \\
\hline Total & $\mathbf{5 0}$ & $\mathbf{2 8 . 2 2 9}$ \\
\hline
\end{tabular}

Sumber: Pengolah Data Excel 
Tabel 5. Analisa Nilai Rata-Rata Nilai Variabel Video Comments dan Video Views Akun Nissan Indonesia

\begin{tabular}{|c|c|r|}
\hline No & Video Comments & \multicolumn{1}{c|}{ Video Views } \\
\hline $\mathbf{1}$ & 9 & 773 \\
\hline $\mathbf{2}$ & 17 & 3.509 \\
\hline $\mathbf{3}$ & 19 & 1.732 \\
\hline $\mathbf{4}$ & 42 & 3.337 \\
\hline $\mathbf{5}$ & 79 & 7.688 \\
\hline $\mathbf{6}$ & 481 & 248.000 \\
\hline $\mathbf{7}$ & 19 & 3.096 \\
\hline $\mathbf{8}$ & 22 & 11.905 \\
\hline $\mathbf{9}$ & 448 & 65.397 \\
\hline $\mathbf{1 0}$ & 819 & 182.000 \\
\hline Total & $\mathbf{1 9 6}$ & $\mathbf{5 2 . 7 4 4}$ \\
\hline
\end{tabular}

Setelah menghitung nilai rata-rata tersebut, maka akan menemukan hasil akhir nilai rata-rata dari variabel video comments dan video views.

Tabel 6. Nilai Variabel Pada Akun Youtube 5 Perusahaan Produsen Mobil Terkemuka Di Indonesia

\begin{tabular}{|c|c|l|l|c|c|}
\hline Variable & Toyota Indonesia & $\begin{array}{l}\text { Welove Honda } \\
\text { Indonesia }\end{array}$ & $\begin{array}{l}\text { Daihatsu } \\
\text { Sahabatku }\end{array}$ & Suzuki Global & Nissan Indonesia \\
\hline Video Comments & 8 & 29 & 15 & 50 & 196 \\
\hline Video Views & 256268 & 1088283 & 25320 & 28229 & 52744 \\
\hline
\end{tabular}

Sumber: Pengolah Data Excel

Pada akun TikTok terdapat 10 rasio yang relevan digunakan untuk mengukur kredibilitas pada masing-masing akun. Namun pada penelitian kali ini hanya berfokus untuk menghitung Video Comments to Video Views Ratio. Untuk menghitung kredibilitas dari masing-masing akun Youtube setiap Perusahaan Produsen Mobil, peneliti menghitung dengan cara: variabel 1 akan dibagi dengan variabel 2 , sehingga ditemukan hasil analisisa dari rasio tersebut. 
Tabel 7. Hasil Perhitungan Rasio Akun Youtube 5 Perusahaan Produsen Mobil Terkemuka Di Indonesia

\begin{tabular}{|c|c|c|c|c|c|c|}
\hline No & Ratio & Toyota & Welove Honda & Daihatsu & Nissan \\
\hline 1 & Video Comments to Video Views Ratio & 0,00003122 & 0,00002665 & 0,00059242 & Sahabatku & Indonesia \\
\hline
\end{tabular}

Sumber: Pengolah Data Excel

Video Comments to Video Views Ratio memiliki karakteristik yang tinggi, artinya semakin tinggi nilai yang dihasilkan maka semakin baik kredibilitas dari performa akun tersebut. Untuk memberikan peringkat pada masing-masing Perusahaan Produsen Mobil, peneliti memberikan angka 5 kepada vendor yang mendapatkan nilai tertinggi dan angka 1 untuk Perusahaan Produsen Mobil yang mendapatkan nilai terendah. Berikut merupakan tabel urutan nilai yang dihasilkan oleh masing-masing Perusahaan Produsen Mobil.

Tabel 8. Nilai Rasio Akun Youtube 5 Perusahaan Produsen Mobil Terkemuka Di Indonesia

\begin{tabular}{|c|c|c|c|c|c|c|}
\hline No & Ratio & $\begin{array}{c}\text { Toyota } \\
\text { Indonesia }\end{array}$ & $\begin{array}{c}\text { Welove Honda } \\
\text { Indonesia }\end{array}$ & $\begin{array}{c}\text { Daihatsu } \\
\text { Sahabatku }\end{array}$ & $\begin{array}{l}\text { Suzuki } \\
\text { Global }\end{array}$ & $\begin{array}{c}\text { Nissan } \\
\text { Indonesia }\end{array}$ \\
\hline 1 & Video Comments to Video Views Ratio & 2 & 1 & 3 & 4 & 5 \\
\hline
\end{tabular}

Sumber: Pengolah Data Excel

Dari Tabel Nilai Rasio Akun Youtube dari 5 Perusahaan Produsen Mobil Terkemuka Di Indonesia dapat simpulkan bahwa akun Youtube Nissan Indonesia mendapatkan nilai tertinggi untuk rasio Video Comments to Video Views. Sedangkan akun Youtube Welove Honda Indonesia mendapatkan nilai terendah untuk rasio ini. Jadi, pada penelitian ini Nissan Indonesia memiliki kredibilitas performa yang lebih baik dibandingkan dengan Perusahaan Produsen Mobil yang lainnya. 


\section{KESIMPULAN}

Tujuan dari penelitian ini adalah mengetahui kredibilitas performa dari akun Youtube dari 5 Perusahaan Produsen Mobil Terkemuka Di Indonesia menggunakan Video Comments to Video Views Ratio. 5 Perusahaan Produsen Mobil Terkemuka Di Indonesia tersebut diantaranya yaitu: Toyota Indonesia, Welove Honda Indonesia, Daihatsu Sahabatku, Suzuki Global, dan Nissan Indonesia. Dari kelima Perusahaan Produsen Mobil tersebut dapat disimpulkan bahwa:

1. Peringkat pertama diraih oleh Perusahaan mobil Nissan Indonesia dengan nilai tertinggi yaitu 0,00371606

2. Peringkat kedua diraih oleh Perusahaan mobil Suzuki Global dengan nilai 0,00177123

3. Peringkat ketiga diraih oleh Perusahaan mobil Daihatsu Sahabatku dengan nilai 0,00059242

4. Peringkat keempat diraih oleh Perusahaan mobil Toyota Indonesia dengan nilai 0,00003122

5. Peringkat kelima diraih oleh Perusahaan mobil Welove Honda Indonesia dengan nilai terendah yaitu 0,00002665 


\section{DAFTAR PUSTAKA}

Hager, G., \& Wellein, G. (2021). PENGARUH MEDIA SOSIAL TERHADAP PERUBAHAN SOSIAL MASYARAKAT DI INDONESIA. Introduction to High Performance Computing for Scientists and Engineers, 194-210. https://doi.org/10.1201/ebk1439811924-14

Hendika Permana, I. P. (2021). Analisis Rasio Pada Akun Youtube Untuk Penelitian Kualitatif Menggunakan Metode Ekploratif. Jurnal IImiah Media Sisfo, 15(1), 40. https://doi.org/10.33998/mediasisfo.2021.15.1.970

Kumparan. (2020). Variabel Penelitian: Pengertian, Jenis. https://kumparan.com/berita-hariini/variabelpenelitian-pengertian-jenis-dan-contohnya-1ul9vdTWwAS/full

Mudjiyanto, B. (2018). Tipe Penelitian Eksploratif Komunikasi. Jurnal Studi Komunikasi Dan Media, 22(1), 65. https://doi.org/10.31445/jskm.2018.220105

Rosana, A. S. (2010). Kemajuan Teknologi Informasi dan Komunikasi dalam Industri Media di Indonesia. Gema Eksos, 5(2), 146-148. https://www.neliti.com/id/publications/218225/kemajuanteknologiinformasi-dan-komunikasi-dalam-industri-media-di-indonesia

Tagarberita. (2020). 5 Perusahaan Produsen Mobil Terkemuka di Indonesia. https://www.tagarberita.com/2020/05/perusahaan-produsen-mobil-terkemuka.html

Youtube, T. U. T. (2005). Wikipedia, Youtube. https://id.wikipedia.org . Diakses pada tanggal 20 Januari 2018 14. 14-50. 